\title{
A nalysis of the advantages of an aerodynamic compensator in contactless space debris removal
}

\author{
Institute of Technical Mechanics \\ of the National Academy of Sciences of U kraine and the State Space Agency of U kraine \\ 15 Leshko-Popel St., Dnipro 49005, Ukraine; e-mail: oafokov@ukr.net
}

\begin{abstract}
A modified scheme of the known technology for contactless space debris removal, which is called Ion Beam Shepherd, is considered. This scheme uses an aerodynamic compensator in order to reduce the propellant consumption of the additional electrojet thruster of the shepherd spacecraft. The thruster serves to compensate the spacecraft motion caused by the action of the main electrojet thruster, whose ion plume "brakes" the space debris object. The aerodynamic compensator significantly increases the spacecraft cross-sectional area compared to the space debris object one. This fact, together with the aerodynamic perturbations acting in the direction perpendicular to the orbital plane, calls for estimating the propellant consumption of the control system thruster to maintain the required position of the spacecraft relative to the space debris object in that direction. The goal of this article is to identify the advantages of using the aerodynamic compensator in space debris removal from low Earth orbits using the Ion Beam Shepherd technology. The tasks of the study are to estimate the reduction in the cost of the momentum of the additional electrojet thruster during contactless space debris object de-orbiting due to the use of the aerodynamic compensator and the additional cost of the momentum of the thruster of the spacecraft - space debris object relative position control system to correct deviations perpendicular to the orbital plane. Using a number of simplifying assumptions, integral estimates of these costs are obtained. Using these cost estimates, it is shown that the use of an aerodynamic compensator is advantageous in terms of the cost of the saved electrojet thruster propellant (xenon) regardless of the type of the spacecraft control system thruster.
\end{abstract}

Keywords space debris removal, Ion Beam Shepherd concept, aerodynamic compensator, momemtum, benefits of use.

1. Alpatov A. P., Maslova A. I., Khoroshylov S. V. Contactless De-Orbiting of Space Debris by the lon Beam. Dynamics and Control. Beau Bassin: LAP Lambert Academic Publishing, 2018. 330 pp. https://doi.org/10.15407/akademperiodyka.383.170

2. Bombardelli C., Pelaez J. Ion beam shepherd for contactless space debris removal. Journal of Guidance, Control and Dynamics. 2011. V. 34. No. 3. Pp. 916 - 920. https://doi.org/10.2514/1.51832

3. Bombardelli C., Merino M., Ahedo E., Pelaez J., Urrutxua H., Iturri-Torreay A., Herrera-Montojoy J. Ariadna call for ideas: Active removal of space debris ion beam shepherd for contactless debris removal. ESA Technical Report. 2011. 90 pp.

4. Khoroshylov S. V. Relative motion control system of spacecraft for contactless space debris removal. Sci. Innov. 2018. V. 14. No. 4. Pp. 5 - 17. (in Ukrainian).

https://doi.org/10.15407/scin14.04.005

5. Khoroshylov S. V. The algorithm to control the in-plane relative motion of a spacecraft for contactless space debris removal. Space Sci. \& Technol. 2019. V. 25. No. 1. Pp 14 - 26. (in Russian). https://doi.org/10.15407/scine14.04.005

6. Alpatov A., Khoroshylov S., Bombardelli C. Relative control of an ion beam shepherd satellite using the impulse compensation thruster. Acta Astronautica. 2018. V. 151. Pp. 543 - 554. https://doi.org/10.1016/j.actaastro.2018.06.056

7. Alpatov A. P., Svorobin D. S., Skoryk O. D. System for contactless removal of space debris from near-earth orbits using aerodynamic compensator. Teh. Meh. 2016. No. 3. Pp. 51 - 56 (in Ukrainian).

8. Svorobin D. S., Fokov A. A., Khoroshylov S. V. Feasibility analysis of aerodynamic compensator application in contactless space debris removal. Aerospace Technic and Technology. 2018. No. 6. Pp 4 - 11. (in Russian).

9. Khoroshylov S. Out-of-plane relative control of an ion beam shepherd satellite using yaw attitude deviations. Acta Astronautica. 2019. V. 164. Pp. 254 - 261. 
https://doi.org/10.1016/j.actaastro.2019.08.016

10. Lawden D. F. Optimal Trajectories for Space Navigation. London: Butterworths, 1963.

11. Vallado D. A. Fundamentals of Astrodynamics and Applications. Hawthorne, CA: Microcosm Press, 2007.

12. Reid T, Misra A. Formation flight of satellites in the presence of atmospheric drag. J. Aerosp. Eng. Sci. Appl. 2011. V. 3. No. 1. Pp. 64 - 91. https://doi.org/10.7446/jaesa.0301.05

13. Markley F. L., Crassidis J. L. Fundamentals of Spacecraft Attitude Determination and Control. New York: Springer Science + Business Media, 2014. 486 pp. https://doi.org/10.1007/978-1-4939-0802-8

14. Ryzhkov V.V., Sulinov A.V. Propulsion systems and low-thrust rocket engines based on various physical principles for control systems of small and micro-spacecraft. Vestnik of Samara University. Aerospace and Mechanical Engineering. 2018. V. 17. No. 4. Pp. 115-128. (in Russian). https://doi.org/10.18287/2541-7533-2018-17-4-115-128

Received on November 16, 2020, in final form on November 30, 2020 